\title{
Treatment completion and anxiety sensitivity effects on smoking cessation outcomes
}

\author{
Carmela Martínez-Vispo ${ }^{\mathrm{a}, *}$, Ana López-Durán ${ }^{\mathrm{a}, \mathrm{c}}$, Rubén Rodríguez-Cano ${ }^{\mathrm{b}}$, Carmen Senra ${ }^{\mathrm{c}}$, \\ Elisardo Becoña ${ }^{\text {a,c }}$ \\ ${ }^{a}$ Smoking Cessation and Addictive Disorders Unit, Department of Clinical Psychology and Psychobiology, Faculty of Psychology, University of Santiago de Compostela, \\ Spain \\ ${ }^{\mathrm{b}}$ Department of Behavioral Science, The University of Texas MD Anderson Cancer Center, USA \\ ${ }^{\mathrm{c}}$ Department of Clinical Psychology and Psychobiology, Faculty of Psychology, University of Santiago de Compostela, Spain
}

\section{A R T I C L E I N F O}

\section{Keywords:}

Smoking cessation

Treatment completion

Anxiety sensitivity

Physical concerns

\begin{abstract}
A B S T R A C T
Introduction: Treatment completion is associated with abstinence outcomes in smoking cessation interventions. Previous research has stated that anxiety sensitivity (AS) is associated with smoking-related variables and smoking-cessation outcomes. To date, research has not examined the interaction between AS and treatment completion on smoking-cessation outcomes over time. This study aims to examine the main and the interactive effects of treatment completion and AS (total score and specific dimensions) on smoking-cessation outcomes at 3, 6-, and 12-month follow-ups.

Method: The sample consisted of 210 smokers enrolled in an eight-session smoking-cessation cognitivebehavioral treatment $\left(62.1 \%\right.$ women; $\mathrm{M}_{\mathrm{age}}=45.2$, SD $\left.=11.0\right)$. Participants were classified as completers (attended the eight treatment sessions) and non-completers (attended $\leq 7$ sessions). Abstinence was biochemically confirmed.

Results: Main effects indicated that completers had a higher likelihood of being abstinent over time when compared to non-completers. Regarding AS, those with greater AS-Physical Concerns had lower abstinence rates. Besides, a significant interaction between treatment completion, time and AS-Physical Concerns was found. Particularly, completers with greater AS-Physical Concerns had a higher likelihood of being abstainers than noncompleters over time, while no significant differences were found for those with lower AS-Physical Concerns. Conclusion: These data highlight the relevance of AS-Physical levels and smoking-cessation treatment completion on abstinence outcomes over time among treatment-seeking smokers.
\end{abstract}

\section{Introduction}

Smoking is a worldwide major public health concern due to its associated consequences in terms of mortality, health, and quality of life (Reitsma et al., 2017; U.S. Department of Health and Human Services (U.S.D.H.H.S.), 2020). Smoking cessation treatments have currently demonstrated their effectiveness (Patnode et al., 2015) but despite effective treatment options to help smokers quit, a significant number of smokers continue to smoke and relapse after quitting (Babb, Malarcher, Schauer, Asman, \& Jamal, 2017). Treatment completion has been shown to be positively related to smoking-cessation outcomes (Garey et al., 2020; Iliceto, Fino, Pasquariello, D’Angelo Di Paola, \& Enea, 2013), and even attending a greater number of sessions increases the likelihood of short-term abstinence (Dorner, Trostl, Womastek, \& Groman, 2011).

In light of this evidence, the potential role of some factors interacting with treatment effects has received researchers' attention. Certainly, knowing the moderating effects of potentially modifiable variables on treatment completion has important clinical implications. In particular, identifying these moderators would help to design tailored treatment components that address such variables. One factor that could moderate the effect of treatment completion is Anxiety Sensitivity (AS) (Leventhal \& Zvolensky, 2015). AS, defined as the fear of anxiety symptomatology and related bodily sensations (Reiss, Peterson, Gursky, \& McNally, 1986), is considered as a vulnerability factor for the onset, maintenance,

\footnotetext{
* Corresponding author at: Smoking and Addictive Disorders Unit, Department of Clinical Psychology and Psychobiology, Faculty of Psychology, University of Santiago de Compostela, 15782 Santiago de Compostela, Spain.

E-mail address: carmela.martinez@usc.es (C. Martínez-Vispo).
} 
and severity of a wide range of emotional disorders such as depression and anxiety, which are closely related to smoking (Morissette et al., 2007; Naragon-Gainey, 2010).

AS-smoking-related research has shown that high AS smokers tend to report more difficulties during past quit attempts (Guillot, Zvolensky, \& Leventhal, 2015), as well as to perceive more cessation barriers and abstinence achievement as more difficult than those with lower AS (Gonzalez, Zvolensky, Vujanovic, Leyro, \& Marshall, 2008; Guillot, Leventhal, Raines, Zvolensky, \& Schmidt, 2016). Furthermore, some studies have found poor smoking-cessation outcomes in smokers high in AS (Assayag, Bernstein, Zvolensky, Steeves, \& Stewart, 2012) and increased odds of drop-out of study participation during a self-guided quitting attempt (Langdon, Farris, Hogan, Grover, \& Zvolensky, 2016). For instance, Assayag et al. (2012) found that participants who maintained maladaptive AS levels from pre- to post-treatment had significantly lower quit rates compared with those who reduced their pre-treatment maladaptive AS levels to normative AS levels at posttreatment (i.e., at 1 -month post-treatment, $20.8 \%$ vs. $46.2 \%$ were abstinent, respectively).

Most of these studies have investigated AS considering it as a single construct (Leventhal \& Zvolensky, 2015) but research in clinical and non-clinical samples has consistently found three dimensions (Bernstein et al., 2010; Kemper et al., 2012; Taylor et al., 2007) that could be differentially influencing smoking-related behaviors. These three dimensions are: AS-Physical Concerns (fear of anxiety-related physical symptoms), AS-Cognitive Concerns (fears of mental incapacitation or losing control of mental processes in the context of stress or anxiety symptoms), and AS-Social Concerns (fear that others may notice anxiety symptoms). These three dimensions have shown high validity in treatment-seeking smokers, confirming the multidimensionality of this construct and the potential relevance of considering its relation to smoking variables and cessation outcomes (Farris, DiBello et al., 2015).

AS dimensions are associated with specific smoking-related characteristics. In this regard, AS-Physical Concerns has been related to greater cigarette dependence (Svicher, Zvolensky, \& Cosci, 2018), more intense tobacco-withdrawal symptoms (Guillot et al., 2015), and perceiving more barriers to quit smoking (Langdon et al., 2018). When examining AS-Cognitive Concerns, studies have shown that it is associated with greater expectations of smoking-related negative reinforcement, such as negative affect reduction (Guillot et al., 2015), more perceived barriers to quitting, and more problems when trying to quit (Zvolensky, Bakhshaie, Shepherd, Peraza et al., 2019). AS-Social Concerns has been connected to stronger social-related positive reinforcement smoking expectations (Guillot et al., 2015). Although the available evidence supports the notion of the differential impact that each of these three dimensions could have on smoking-related variables, no previous study has examined their main and interactive effect with treatment completion on abstinence outcomes over time. This knowledge would allow progress in the refinement of smoking-cessation treatments.

Therefore, the current study sought to analyze: (1) the main effects of treatment completion and AS (total score and specific dimensions), and (2) the effect of the interaction between treatment completion and AS (total score and specific dimensions) on smoking-cessation outcomes over time.

\section{Materials and methods}

\subsection{Participants}

Participants were 210 smokers enrolled in a smoking-cessation cognitive-behavioral treatment conducted in Spain. The data of this study are derived from a more extensive investigation of a randomized clinical trial for smoking cessation (NCT Identifier02844595), which has been published previously (Becoña et al., 2017; Martínez-Vispo et al., 2019). The total sample of the main trial was composed of 275 treatment-seeking smokers but for the aims of the present study, only those participants who received active smoking-cessation treatment and who had attended at least the first session were included. The inclusion criteria to participate were: (a) being current daily smokers (at least eight cigarettes per day), (b) aged 18 or more, (c) wishing to participate in the treatment program, and (d) providing written informed consent. Participants were excluded if they had a diagnosis of severe mental disorder (bipolar disorder or psychotic disorder) or a non-nicotine substance use disorder (alcohol, cannabis, stimulants, hallucinogens, or opioids), had participated in the same or similar treatment over the previous year, had received an effective pharmacological treatment to quit smoking over the previous year, had a high life-risk pathology (i.e., recent myocardial infarction), or used tobacco products other than combustible cigarettes.

\subsection{Instruments}

Demographics and smoking-related variables were assessed at treatment baseline. A semi-structured interview was conducted to gather information about personal data, tobacco use, and mental health. Besides, the following questionnaires were used:

- Smoking Habit Questionnaire (Becoña, 1994). This instrument consists of 56 items assessing sociodemographics and smoking-related variables (i.e., years smoking).

- Anxiety Sensitivity Index 3 (ASI-3; Taylor et al., 2007; Sandín, Valiente, Chorot, \& Santed Germán, 2007). This 18-item self-report assesses fear of anxiety-related experiences/symptoms. The ASI Total Scale is composed of three subscales: AS-Physical Concerns, AS-Cognitive Concerns, and AS-Social Concerns. In the present sample, Cronbach's alpha was 0.91 for the total score, 0.89 for the AS-Physical Concerns subscale; 0.85 for the AS-Cognitive Concerns subscale; and 0.81 for the AS-Social Concerns subscale.

- Fagerström Test of Cigarette Dependence (FTCD, Heatherton, Kozlowski, Frecker, \& Fagerström, 1991; Becoña \& Vázquez, 1998). This 6-item instrument assesses cigarette dependence, with higher scores indicating greater cigarette dependence. Cronbach's alpha was 0.65 in this sample.

- Beck Anxiety Inventory (BAI, Beck \& Steer, 1993; Sanz \& Navarro, 2003). This instrument is composed of 21 items assessing anxiety symptomatology severity. Cronbach's alpha was 0.92 in the present sample.

- The Beck Depression Inventory (BDI-II, Sanz \& Vazquez, 2011; Beck et al., 1996). This is a 21-item self-report measuring current depressive symptoms. Cronbach's alpha was 0.90 in the present sample.

\subsection{Procedure}

\subsubsection{Recruitment}

Participants were recruited through the media, posters in healthcare centers, word of mouth, or referred to the unit by primary care physicians or other specialized services of the public healthcare system. Those who agreed to take part in the study signed written informed consent. Participants meeting the inclusion criteria were assessed through a faceto-face interview, also filling in a set of questionnaires (described above). Next, participants were randomized to one of three conditions: (a) a standard smoking-cessation cognitive-behavioral treatment (SCBSCT), (b) a standard smoking-cessation cognitive-behavioral treatment with components of behavioral activation (SCBSCT-BA), and (c) a wait-list control group. For the present study's purpose, we only included those participants randomized to conditions (a) and (b).

\subsubsection{Interventions}

Active conditions ( $a$ and $b$ ) comprised eight weekly group sessions following a cognitive-behavioral approach (Becoña, 2007), which includes components such as smoking self-report, information about 
tobacco, nicotine fading, stimulus control, activities to prevent withdrawal syndrome, physiological feedback through $\mathrm{CO}$ in expired air, and relapse-prevention strategies. The experimental condition (b) also included behavioral activation components targeting mood and engagement in non-smoking-related rewarding activities. Neither nicotine replacement therapy nor smoking-cessation pharmacotherapy were used.

These interventions were conducted by two trained therapists (Master's level in Counseling Psychology) with experience in the application of smoking-cessation interventions. The detailed trial rationale and protocol have been published previously (Becoña et al., 2017).

\subsubsection{Smoking outcomes and treatment completion definitions}

For smoking status, we created two categories: (a) abstainers and (b) smokers. Participants were considered to be abstainers if they reported abstinence, not even a puff, for $\geq 30$ days at 3-, 6- and 12-month followups, and had an expired Carbon Monoxide (CO) reading of $<6$ parts per million (Benowitz et al., 2019). CO measurement was conducted through the Micro + Smokerlyzer (Bedfont Scientific Ltd, Maidstone, Kent, UK). Participants who did not meet this criterion, who reported smoking, or who missed the follow-up were classified as smokers.

Regarding treatment completion, participants were classified as completers if they attended all eight treatment sessions and noncompleters if they attended seven or fewer sessions.

The study was approved by the Bioethics Committee of the University of Santiago de Compostela.

\subsection{Data analyses}

Descriptive analysis of the demographic and smoking-related variables was conducted.

Between-group comparisons (completers vs. non-completers) for abstinence outcomes at the 3-, 6-, and 12-month follow-ups were conducted using chi-square $\left(\chi^{2}\right)$ tests. Cramer's $V$ was used to determine the effect sizes of such differences.

We conducted a set of logistic regression models using Generalized Estimating Equations (GEE). GEE is specially indicated for longitudinal data with a categorical repeated measure outcome (Heck, Thomas, \& Tabata, 2012). In these models, the main and interactive effects of AS, treatment completion ( $0=$ non-completion, $1=$ completion $)$ and time (3-, 6-, and 12-month follow-ups) on abstinence outcomes $(1=$ abstainer, $0=$ smoker) were examined. An autoregressive working covariance matrix was used to account for the correlation between repeated measurements on the same individual over the 12-month follow-up. Continuous predictors were mean-centered. The first models included the ASI total score, and the second models included all three AS subscales. Analyses included Odds ratios (ORs) and adjusted ORs at 95\% confidence level. Adjusted ORs accounting for theoreticaland clinical-relevant variables for smoking abstinence (i.e., age, sex, treatment condition, cigarette dependence [FTCD], depressive symptoms [BDI-II], and anxiety symptoms [BAI]) were calculated (Japuntich et al., 2011; Lee, Hayes, McQuaid, \& Borrelli, 2010; Nollen et al., 2013; Rodríguez-Cano et al., 2016). Post hoc analyses were run for significant interactions using crosstabs to examine the effect of treatment completion on smoking status in each follow-up at high versus low (75 and 25 percentile) levels of AS.

All statistical analyses were conducted using the SPSS software, version 24. A $p$-value of $\leq 0.05$ was used as a test of statistical significance.

\section{Results}

\subsection{Descriptive analysis}

The 210 smokers who participated in the study reported having smoked an average of 19.02 cigarettes per day $(S D=7.33)$, having smoked their first cigarette at 15.83 years of age $(S D=3.17)$, and an average of 26.26 years $(S D=11.49$ ) being daily smokers. Of the total sample, $87.1 \%$ of participants attended at the end of treatment, $74.8 \%$ at 3-months, $68.1 \%$ at 6 -months, and $61.9 \%$ at the 12 -month follow-up. Descriptive statistics of the study variables are presented in Table 1.

\subsection{Main effects of treatment completion, AS and time on smoking} outcomes

Abstainers at 3- $\left(\chi^{2}=20.750, p \leq 0.001\right.$, Cramers $\left.^{\prime} V=0.310\right), 6-\left(\chi^{2}\right.$ $=12.803, p \leq 0.001$, Cramers' $V=0.247)$, and 12-month follow-up $\left(\chi^{2}\right.$ $=11.809, p \leq 0.001$, Cramers' $V=0.237$ ) were more likely to complete the treatment than smokers (Table 2). Effect sizes of such differences according to Cramer's $V$ were small to medium over the one year period (Cohen, 1988).

GEE analysis showed that treatment completion predicted being abstinent over time both in the unadjusted and adjusted models (Table 3).

When including the ASI total score (Table 3, Model 1), both adjusted and unadjusted models showed that the total AS score was not significantly related to abstinence outcomes. There was a significant effect for time related to a lower likelihood of being abstinent over time in unadjusted (OR $=0.83$ [95\% CI: $0.74-0.92] ; p<.001$ ) and adjusted (OR $=0.82$ [95\% CI: $0.72-0.92] ; p<.001$ ) models.

Regarding analysis including all three ASI subscales (Table 3, Model 2), results indicated that greater AS-Physical Concerns was related to a lower likelihood of being abstinent in unadjusted (OR $=0.92$ [95\% CI: $0.86-0.99] ; p=.018$ ) and adjusted (OR $=0.91$ [95\% CI: $0.85-0.98$ ]; $p$ $=.017$ ) models, but neither AS-Cognitive Concerns nor AS-Social Concerns were significantly associated with abstinence outcomes. Again, in both models there was a significant effect of time on abstinence outcomes (OR $=0.83$ [95\% CI: $0.74-0.92] ; p<.001$; and OR $=0.82[95 \%$ CI: $0.73-0.92] ; p<.001$, respectively).

\subsection{Treatment completion and AS interactive effects on abstinence outcomes}

Both adjusted and unadjusted models with the ASI total score (Table 3, Model 1) showed that the interaction between treatment

Table 1

Descriptive data of study variables.

\begin{tabular}{ll}
\hline & $M(S D) / \%(n)$ \\
\hline Age & $45.2(11.0)$ \\
Sex (female) & $62.4(131)$ \\
Education (University) & $40.5(85)$ \\
Marital status & \\
Married & $52.9(111)$ \\
Single & $30.5(64)$ \\
Divorced/separated & $12.4(26)$ \\
Widowed & $4.3(9)$ \\
Employment (yes) & $57.6(121)$ \\
FTCD & $4.8(2.1)$ \\
BAI & $10.0(9.8)$ \\
BDI-II & $10.5(9.1)$ \\
ASI-P & $8.2(6.4)$ \\
ASI-C & $4.7(4.9)$ \\
ASI-S & $7.4(5.4)$ \\
ASI-T & $20.2(13.8)$ \\
Nr. of sessions & $6.63(1.9)$ \\
\hline
\end{tabular}

Note: FTCD = Fagerström Test of Cigarette Dependence; BAI = Beck Anxiety Inventory; BDI-II = Beck Depression Inventory; ASI-P = Anxiety Sensitivity Index Physical Concerns; ASI-C = Anxiety Sensitivity Index Cognitive Concerns; ASI-S = Anxiety Sensitivity Index Social Concerns; ASI-T = Anxiety Sensitivity Index Total scale. ${ }^{*} p<.05 ;{ }^{* * *} p<.01 ;{ }^{* * * *} p<.001$. 
Table 2

Abstinence outcomes according to treatment completion.

\begin{tabular}{|c|c|c|c|c|c|}
\hline & $\begin{array}{l}\text { Non- } \\
\text { completers }\end{array}$ & Completers & $\chi^{2}$ & $\begin{array}{l}\text { Cramer's } \\
V\end{array}$ & $p$ \\
\hline & $\%(\mathrm{n})$ & $\%(\mathrm{n})$ & & & \\
\hline $\begin{array}{l}\text { 3-month } \\
\text { follow-up }\end{array}$ & 17.6 (19) & $47.1(48)$ & 20.964 & 0.316 & 0.001 \\
\hline $\begin{array}{l}\text { 6-month } \\
\text { follow-up }\end{array}$ & $14.8(16)$ & 36.3 (37) & 12.803 & 0.247 & 0.001 \\
\hline $\begin{array}{l}\text { 12-month } \\
\text { follow-up }\end{array}$ & $14.8(16)$ & $35.3(36)$ & 11.809 & 0.237 & 0.001 \\
\hline
\end{tabular}

Table 3

Generalized Estimating Equations Models for abstinence outcomes.

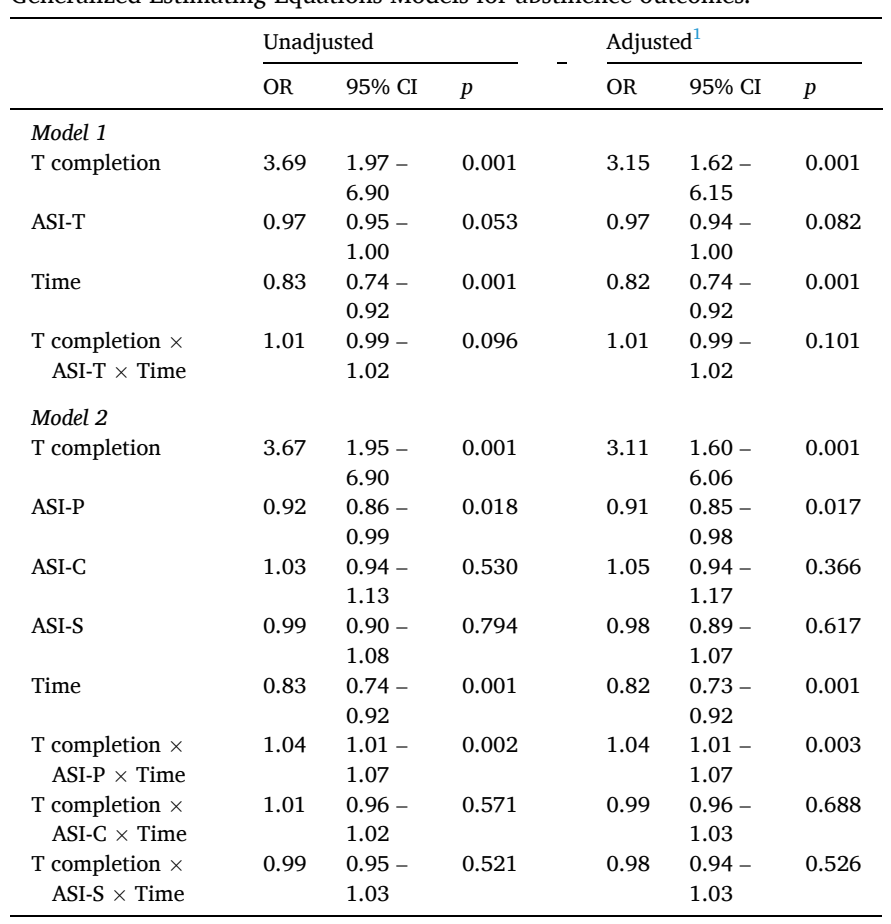

Note: ASI-T $=$ Anxiety Sensitivity Index Total scale; ASI-P = Anxiety Sensitivity Index Physical Concerns; ASI-C = Anxiety Sensitivity Index Cognitive Concerns; ASI-S = Anxiety Sensitivity Index Social Concerns

1 Covariates: age, sex, treatment condition, cigarette dependence (Fagerström Test of Cigarette Dependence); depressive symptoms (Beck Depression Inventory-II), and anxiety symptoms (Beck Anxiety Inventory). completion, AS, and time was not significantly related to abstinence outcomes.

When examining the interaction between treatment completion, all three ASI subscales and time (Table 3, Model 2), the results indicated that only the interaction that contained, AS-Physical Concerns had a significant effect on smoking status in both adjusted and unadjusted models. Post hoc analysis indicate that those participants who completed the treatment and having higher AS-Physical Concerns had a higher likelihood of being abstinent at each follow-up comparing with noncompleters (Fig. 1). However, differences between completers and non-completers with lower AS-Physical Concerns were non-significant at 6- and 12-month follow-ups. Interactions between treatment completion, each of the remaining AS subscales (AS-Cognitive Concerns and AS-Social Concerns), and time were not significant.

\section{Discussion}

The present study investigated whether treatment completion and AS were related to abstinence outcomes over time among treatmentseeking smokers enrolled in a smoking cessation treatment, as well as their interactive effect. To our knowledge, this is the first study that examines the moderating effect of AS and treatment completion on abstinence outcomes using biochemically confirmed abstinence over a one-year follow-up after the smoking cessation treatment.

Our findings showed that smoking-cessation treatment completion was strongly related to a higher likelihood of abstinence success after treatment. Similarly to previous research (Dorner et al., 2011; Iliceto et al., 2013), a higher number of attended sessions was positively associated with abstinence during a one-year period after smokingcessation treatment, even when considering other relevant variables.

When examining the predictive value of AS, our data indicated that the ASI total score did not significantly predict abstinence outcomes. However, when examining the effect of the AS dimensions on smoking status, the models showed that greater AS-Physical Concerns was a significant predictor of a lower likelihood of being abstinent over time. This finding provides new insight by showing that the AS dimensions, rather than the global concept of AS, could be specifically related to smoking outcomes. Furthermore, it is noteworthy that, even when adjusting by relevant covariates such as tobacco dependence, anxiety, and depression symptoms, which are also related to abstinence outcomes (Ferguson et al., 2003; Piper, Cook, Schlam, Jorenby, \& Baker, 2011; Stepankova et al., 2017), such an effect remained statistically significant. These results could be related to the fact that participants with higher AS-physical concerns tend to report greater interoceptive threats related to smoking abstinence and to perceive more barriers or stressors to smoking cessation (Farris, Langdon, DiBello, \& Zvolensky, 2015; Zvolensky, Bakhshaie, Shepherd, Peraza et al., 2019; Zvolensky, Bakhshaie, Shepherd, Garey et al., 2019). Therefore, these smokers

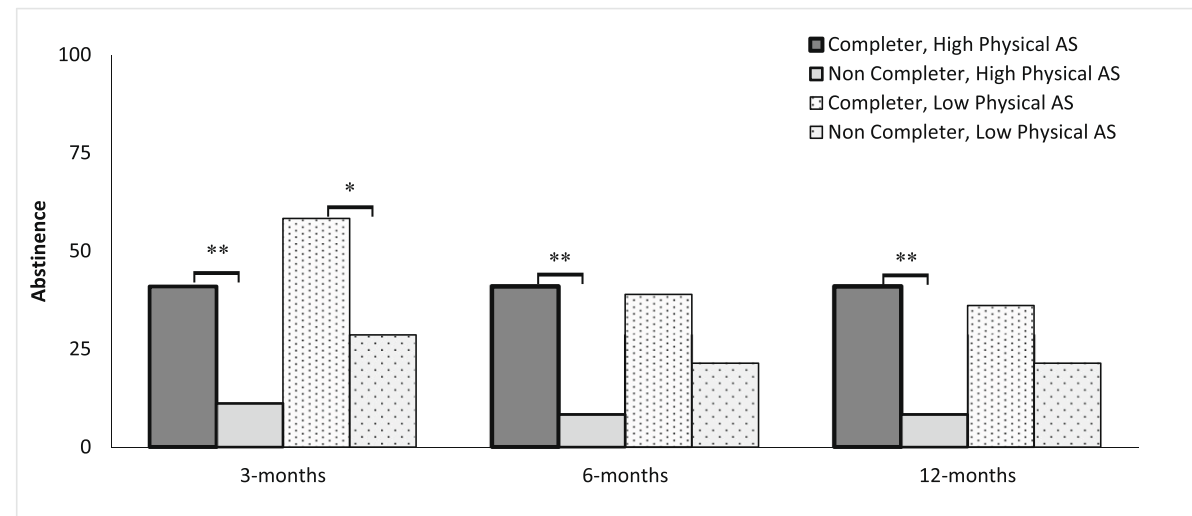

Fig. 1. Abstinence according to treatment completion and AS-Physical Concerns scores over time. Note: AS $=$ Anxiety Sensitivity. ${ }^{*} p<0.05 ;{ }^{*} p<0.01$. 
could discontinue their quit attempt due to the difficulties associated with abstinence maintenance. Besides, AS-physical concerns may boost withdrawal symptoms (Zvolensky, Farris, Guillot, \& Leventhal, 2014), possibly due to smokers' expectations about the distress associated with interoceptive and other internal processes related to quitting (Farris, Leventhal, Schmidt, \& Zvolensky, 2015; Zvolensky et al., 2014). Thus, AS-Physical Concerns could contribute to undermining the participants' motivation to be abstinent. Finally, it has been suggested that smokers with greater AS-Physical Concerns are more prone to smoking in response to negative affect (Guillot et al., 2016), which could be associated with smoking over time.

Our findings did not show a significant effect of AS-Cognitive and ASSocial Concerns, despite that, in some previous studies, AS-Cognitive Concerns had also appeared as a significant variable related to smoking variables (Assayag et al., 2012; Guillot et al., 2016). This discrepancy could be due to the fact that, as suggested in previous literature, smokers with higher levels of AS-Physical Concerns could focus particularly on the nature and meaning of the experienced physical anxiety symptoms, leading to lower attention to anxiety-related cognitions (Langdon et al., 2018). Future studies are warranted to explore the complex ways in which the AS dimensions interact and affect abstinence outcomes.

The present study also showed a significant interactive effect of treatment completion, the AS-Physical Concerns dimension, and time on abstinence outcomes, such that individuals with higher AS-Physical Concerns at baseline who complete the smoking-cessation treatment presented greater abstinence rates at 3-, 6-, and 12-month follow-ups comparing with non-completers. These results underline the relevance of maintaining in treatment those participants with higher AS-physical concerns. Clinically, the present findings show the potential interest of including treatment components to enhance treatment retention since completing smoking cessation treatment emerged as a significant predictor of smoking outcomes over time. Besides, this study showed that treatment completion could be especially relevant for those participants with greater AS-physical concerns, highlighting the importance of considering both variables in smoking cessation interventions. Moreover, including intervention components to reduce AS-physical concerns may contribute to improving abstinence rates. In fact, there is preliminary evidence favoring AS reduction interventions for smoking cessation (Smits et al., 2016; Zvolensky, Yartz, Gregor, Gonzalez, \& Bernstein, 2008). More research is needed to determine whether targeting specific AS dimensions may be beneficial for smoking-cessation interventions. For instance, future work is needed to examine whether the inclusion of specific cognitive-behavioral components targeting physical AS, like training to control physical symptoms of anxiety, interoceptive exposure exercises, or acceptance strategies, could enhance abstinence outcomes. There is also a need to explore whether the inclusion of such components targeting AS during the first intervention sessions could contribute to maintaining these participants in treatment.

The current study has several limitations that should be considered when interpreting these findings. First, the present sample comprises a group of Spanish adult smokers who volunteered to participate in a smoking-cessation treatment and, therefore, findings could not be generalized to other populations of smokers with different ethnic/racial backgrounds. Secondly, self-report measures were utilized as the primary assessment methodology for demographics, smoking-related, and psychological variables, which does not fully prevent biases (e.g., social desirability). Lastly, we only examined the main and interactive effects of treatment completion and AS. However, it would be interesting to analyze such effects on different attendance patterns (i.e., drop-outs, titrators, and completers) like those found by Jacquart et al. (2017).

\section{Conclusions}

Overall, the present findings highlight the relevance of AS-Physical levels and smoking-cessation treatment completion for abstinence outcomes over time among treatment-seeking smokers, even after considering other relevant factors associated with smoking outcomes. The evidence provided by this study encourages further research on the role of AS in quitting processes and continued efforts to enhance treatment completion and target AS in smoking-cessation treatments.

\section{Author statement}

All authors have read and agreed to the published version of the manuscript.

\section{Funding}

This research was supported by the Spanish Ministry of Economy and Competitiveness (Project reference: PSI2015-66755-R) and co-financed by FEDER (European Regional Development Fund; pluri-annual plan 2014-2020).

\section{Role of funding sources}

Spanish Ministry of Economy and Competitiveness had no role in the study design, collection, analysis or interpretation of the data, writing the manuscript, or the decision to submit the paper for publication.

\section{CRediT authorship contribution statement}

Carmela Martínez-Vispo: Conceptualization, Methodology, Formal analysis, Investigation, Data curation, Writing - original draft, Writing review \& editing, Visualization. Ana López-Durán: Conceptualization, Methodology, Validation, Investigation, Visualization, Supervision. Rubén Rodríguez-Cano: Formal analysis, Writing - review \& editing. Carmen Senra: Writing - review \& editing, Supervision. Elisardo Becona: Conceptualization, Methodology, Validation, Investigation, Resources, Data curation, Writing - review \& editing, Visualization, Supervision, Project administration, Funding acquisition.

\section{Declaration of Competing Interest}

The authors declare that they have no known competing financial interests or personal relationships that could have appeared to influence the work reported in this paper.

\section{Acknowledgments}

Ruben Rodriguez-Cano is supported by the Cancer Prevention and Research Institute of Texas (CPRIT) Postdoctoral Fellowship in Cancer Prevention (RP 170259, Drs. Chang and Shete, PIs) and by MD Anderson's Cancer Center Support Grant (CA016672) funded by the National Cancer Institute.

\section{References}

Assayag, Y., Bernstein, A., Zvolensky, M. J., Steeves, D., \& Stewart, S. S. (2012). Nature and role of change in anxiety sensitivity during NRT-aided cognitive-behavioral smoking cessation treatment. Cognitive Behaviour Therapy, 41(1), 51-62. https://doi. org /10.1080/16506073.2011.632437.

Babb, S., Malarcher, A., Schauer, G., Asman, K., \& Jamal, A. (2017). Quitting smoking among adults - United States, 2000-2015. MMWR. Morbidity and Mortality Weekly Report, 65(52), 1457-1464. https://doi.org/10.15585/mmwr.mm6552a1.

Beck, A., Steer, R., \& Brown, G. (1996). Beck Depression Inventory-second edition. Manual. (Texas). The Psychological Corporation.

Beck, A. T., \& Steer, R. (1993). Beck Anxiety Inventory manual. Psychological Corporation.

Becoña, E. (2007). Programa para dejar de fumar [Smoking cessation program]. Nova Galicia Edicións.

Becoña, E., Martínez-Vispo, C., Senra, C., López-Durán, A., Rodríguez-Cano, R., \& Fernández del Río, E. (2017). Cognitive-behavioral treatment with behavioral activation for smokers with depressive symptomatology: Study protocol of a randomized controlled trial. BMC Psychiatry, 17(1). https://doi.org/10.1186/ s12888-017-1301-7. 
Becoña, E., \& Vázquez, F. L. (1998). The Fagerström test for nicotine dependence in a spanish sample. Psychological Reports, 83(3_suppl), 1455-1458. https://doi.org/ 10.2466/pro.1998.83.3f.1455.

Becoña, E. (1994). Evaluación de la conducta de fumar [Assessment of smoking behavior]. In J. L. Graña (Ed.), Conductas Adictivas: Teoría, evaluación y tratamiento. (pp. 403-454). Debate.

Bernstein, A., Stickle, T. R., Zvolensky, M. J., Taylor, S., Abramowitz, J., \& Stewart, S. (2010). Dimensional, categorical, or dimensional-categories: testing the latent structure of anxiety sensitivity among adults using factor-mixture modeling. Behavior Therapy, 41(4), 515-529. https://doi.org/10.1016/j.beth.2010.02.003.

Benowitz, N. L., Bernert, J. T., Foulds, J., Hecht, S. S., Jacob, P., Jarvis, M. J., . Piper, M. E. (2019). Biochemical Verification of Tobacco Use and Abstinence: 2019 Update. Nicotine \& Tobacco Research. https://doi.org/10.1093/ntr/ntz132.

Cohen, J. (1988). Statistical power analysis for the behavioral sciences. Erlbaum.

Dorner, T. E., Trostl, A., Womastek, I., \& Groman, E. (2011). Predictors of short-term success in smoking cessation in relation to attendance at a smoking cessation program. Nicotine \& Tobacco Research, 13(11), 1068-1075. https://doi.org/ 10.1093/ntr/ntr179.

Farris, S. G., DiBello, A. M., Allan, N. P., Hogan, J., Schmidt, N. B., \& Zvolensky, M. J. (2015). Evaluation of the Anxiety Sensitivity Index-3 among treatment-seeking smokers. Psychological Assessment, 27(3), 1123-1128. https://doi.org/10.1037/ pas0000112.

Farris, S. G., Langdon, K. J., DiBello, A. M., \& Zvolensky, M. J. (2015). Why do anxiety sensitive smokers perceive quitting as difficult? The role of expecting "Interoceptive Threat" during acute abstinence. Cognitive Therapy and Research, 39(2), 236-244. https://doi.org/10.1007/s10608-014-9644-6.

Farris, S. G., Leventhal, A. M., Schmidt, N. B., \& Zvolensky, M. J. (2015). Anxiety sensitivity and pre-cessation smoking processes: Testing the independent and combined mediating effects of negative affect-reduction expectancies and motives. Journal of Studies on Alcohol and Drugs, 76(2), 317-325. https://doi.org/10.15288/ jsad.2015.76.317.

Ferguson, J. A., Patten, C. A., Schroeder, D. R., Offord, K. P., Eberman, K. M., \& Hurt, R. D. (2003). Predictors of 6-month tobacco abstinence among 1224 cigarette smokers treated for nicotine dependence. Addictive Behaviors, 28(7), 1203-1218. https://doi.org/10.1016/S0306-4603(02)00260-5.

Gonzalez, A., Zvolensky, M. J., Vujanovic, A. A., Leyro, T. M., \& Marshall, E. C. (2008). An evaluation of anxiety sensitivity, emotional dysregulation, and negative affectivity among daily cigarette smokers: Relation to smoking motives and barriers to quitting. Journal of Psychiatric Research, 43(2), 138-147. https://doi.org/ 10.1016/j.jpsychires.2008.03.002.

Guillot, C. R., Leventhal, A. M., Raines, A. M., Zvolensky, M. J., \& Schmidt, N. B. (2016) Anxiety sensitivity facets in relation to tobacco use, abstinence-related problems, and cognitions in treatment-seeking smokers. Addictive Behaviors, 56, 30-35. https:// doi.org/10.1016/j.addbeh.2016.01.005.

Guillot, C. R., Zvolensky, M. J., \& Leventhal, A. M. (2015). Differential associations between components of anxiety sensitivity and smoking-related characteristics. Addictive Behaviors, 40, 39-44. https://doi.org/10.1016/j.addbeh.2014.08.004.

Heatherton, T. F., Kozlowski, L. T., Frecker, R. C., \& Fagerström, K. O. (1991). The Fagerström Test for Nicotine Dependence: A revision of the Fagerström Tolerance Questionnaire. British Journal of Addiction, 86(9), 1119-1127.

Heck, R. H., Thomas, S. L., \& Tabata, L. N. (2012). Multilevel modeling of categorical outcomes using IBM SPSS. Taylor \& Francis Group. https://psycnet.apa.org/re cord/2012-12992-000.

Iliceto, P., Fino, E., Pasquariello, S., D’Angelo Di Paola, M. E., \& Enea, D. (2013). Predictors of success in smoking cessation among Italian adults motivated to quit. Journal of Substance Abuse Treatment, 44(5), 534-540. https://doi.org/10.1016/j. jsat.2012.12.004.

Jacquart, J., Papini, S., Davis, M. L., Rosenfield, D., Powers, M. B., Frierson, G. M., . Smits, J. A. J. (2017). Identifying attendance patterns in a smoking cessation treatment and their relationships with quit success. Drug and Alcohol Dependence, 174, 65-69. https://doi.org/10.1016/j.drugalcdep.2017.01.007.

Japuntich, S. J., Leventhal, A. M., Piper, M. E., Bolt, D. M., Roberts, L. J., Fiore, M. C., \& Baker, T. B. (2011). Smoker characteristics and smoking-cessation milestones. American Journal of Preventive Medicine, 40(3), 286-294. https://doi.org/10.1016/j. amepre.2010.11.016.

Kemper, C. J., Lutz, J., Bähr, T., Rüddel, H., \& Hock, M. (2012). Construct validity of the Anxiety Sensitivity Index-3 in clinical samples. Assessment, 19(1), 89-100. https:// doi.org/10.1177/1073191111429389.

Langdon, K. J., Bakhshaie, J., Lopez, A., Tavakoli, N., Garey, L., Raines, A. M., Zvolensky, M. J. (2018). Anxiety sensitivity physical and cognitive concerns in relation to smoking-oriented cognition. Journal of Addiction Medicine, 12(3), 212-219. https://doi.org/10.1097/ADM.0000000000000389.

Langdon, K. J., Farris, S. G., Hogan, J. B. D., Grover, K. W., \& Zvolensky, M. J. (2016) Anxiety sensitivity in relation to quit day dropout among adult daily smokers recruited to participate in a self-guided cessation attempt. Addictive Behaviors, 58, 12-15. https://doi.org/10.1016/j.addbeh.2016.02.017.

Lee, C. S., Hayes, R. B., McQuaid, E. L., \& Borrelli, B. (2010). Predictors of retention in smoking cessation treatment among Latino smokers in the Northeast United States. Health Education Research, 25(4), 687-697. https://doi.org/10.1093/her/cyq010.

Leventhal, A. M., \& Zvolensky, M. J. (2015). Anxiety, depression, and cigarette smoking: a transdiagnostic vulnerability framework to understanding emotion-smoking comorbidity. Psychological Bulletin, 141(1), 176-212. DOI:10.1037/bul0000003.
Martínez-Vispo, C., Rodríguez-Cano, R., López-Durán, A., Senra, C., Fernández del Río, E., \& Becoña, E. (2019). Cognitive-behavioral treatment with behavioral activation for smoking cessation: Randomized controlled trial. PLOS ONE, 14(4), e0214252. DOI:10.1371/journal.pone.0214252.

Morissette, S., Tull, M., Gulliver, S., Kamholz, B., \& Zimering, R. (2007). Anxiety, anxiety disorders, tobacco use, and nicotine: a critical review of interrelationships. Psychological Bulletin, 133(2), 245. https://doi.org/10.1037/0033-2909.133.2.245.

Naragon-Gainey, K. (2010). Meta-analysis of the relations of anxiety sensitivity to the depressive and anxiety disorders. Psychological Bulletin, 136(1), 128-150. https:// doi.org/10.1037/a0018055.

Nollen, N. L., Mayo, M. S., Ahluwalia, J. S., Tyndale, R. F., Benowitz, N. L., Faseru, B., .. Cox, L. S. (2013). Factors associated with discontinuation of bupropion and counseling Among African American light smokers in a randomized clinical trial. Annals of Behavioral Medicine, 46(3), 336-348. https://doi.org/10.1007/s12160013-9510-x.

Patnode, C. D., Henderson, J. T., Thompson, J. H., Senger, C. A., Fortmann, S. P., \& Whitlock, E. P. (2015). Behavioral counseling and pharmacotherapy interventions for tobacco cessation in adults, including pregnant women: A review of reviews for thr the U.S. Preventive Services Task Force. Annals of Internal Medicine, 163(8), 608-621. https://doi.org/10.7326/M15-0171.

Piper, M. E., Cook, J. W., Schlam, T. R., Jorenby, D. E., \& Baker, T. B. (2011). Anxiety diagnoses in smokers seeking cessation treatment: relations with tobacco dependence, withdrawal, outcome and response to treatment. Addiction, 106(2), 418-427. DOI:10.1111/j.1360-0443.2010.03173.x.

Reiss, S., Peterson, R. A., Gursky, D. M., \& McNally, R. J. (1986). Anxiety sensitivity, anxiety frequency and the prediction of fearfulness. Behaviour Research and Therapy, 24(1), 1-8. https://doi.org/10.1016/0005-7967(86)90143-9.

Reitsma, M. B., Fullman, N., Ng, M., Salama, J. S., Abajobir, A., Abate, K. H., Gakidou, E. (2017). Smoking prevalence and attributable disease burden in 195 countries and territories, 1990-2015: A systematic analysis from the Global Burden of Disease Study 2015. The Lancet, 389(10082), 1885-1906. https://doi.org/ 10.1016/S0140-6736(17)30819-X.

Rodríguez-Cano, R., López-Durán, A., Fernández del Río, E., Martínez-Vispo, C. Martínez, Ú., \& Becoña, E. (2016). Smoking cessation and depressive symptoms at 1-, 3-, 6-, and 12-months follow-up. Journal of Affective Disorders, 191, 94-99. https:// doi.org/10.1016/j.jad.2015.11.042.

Sandín, B., Valiente, R. M., Chorot, P., \& Santed Germán, M. A. (2007). ASI-3: Nueva escala para la evaluación de la sensibilidad a la ansiedad. Revista de Psicopatología y Psicología Clínica, 12(2). https://doi.org/10.5944/rppc.vol.12.num.2.2007.4036.

Sanz, J., \& Vazquez, C. (2011). Adaptación española del Inventario para Depresión de Beck-II (BDI-II) [Spanish adaptation of the Beck Depression Inventory-II (BDI-II)]. Manual. Pearson.

Sanz, J., \& Navarro, M. E. (2003). Propiedades psicométricas de una versión española del Inventario de ansiedad de Beck (BAI) en estudiantes universitarios. Ansiedad y Estrés, 9, 59-84.

Smits, J. A. J., Zvolensky, M. J., Davis, M. L., Rosenfield, D., Marcus, B. H., Church, T. S., .. Baird, S. O. (2016). The efficacy of vigorous-intensity exercise as an aid to smoking cessation in adults with high anxiety sensitivity: A randomized controlled trial. Psychosomatic Medicine, 78(3), 354-364. https://doi.org/10.1097/ PSY.0000000000000264.

Stepankova, L., Kralikova, E., Zvolska, K., Pankova, A., Ovesna, P., Blaha, M., \& Brose, L. S. (2017). Depression and smoking cessation: Evidence from a smoking cessation clinic with 1-year follow-up. Annals of Behavioral Medicine, 51(3), 454-463. https://doi.org/10.1007/s12160-016-9869-6.

Svicher, A., Zvolensky, M. J., \& Cosci, F. (2018). Study of the relationship between anxiety sensitivity, smoking abstinence expectancies, nicotine withdrawal, and cigarette dependence among daily smokers. Journal of Addictive Diseases, 37(1-2), 55-63. https://doi.org/10.1080/10550887.2018.1542239.

Taylor, S., Zvolensky, M. J., Cox, B. J., Deacon, B., Heimberg, R. G., Ledley, D. R., ... Cardenas, S. J. (2007). Robust dimensions of anxiety sensitivity: Development and initial validation of the Anxiety Sensitivity Index-3. Psychological Assessment, 19(2), 176-188. https://doi.org/10.1037/1040-3590.19.2.176.

U.S. Department of Health and Human Services (U.S.D.H.H.S.). (2020). Smoking Cessation: A Report of the Surgeon General.

Zvolensky, M. J., Bakhshaie, J., Shepherd, J. M., Garey, L., Viana, A. G., \& Peraza, N. (2019). Anxiety symptoms and smoking among Latinx adult smokers: The importance of sensitivity to internal cues in terms of dependence, barriers for quitting, and quit problems. Journal of Behavioral Medicine, 43(1), 88-98. https:// doi.org/10.1007/s10865-019-00059-8.

Zvolensky, M. J., Bakhshaie, J., Shepherd, J. M., Peraza, N., Garey, L., Viana, A. G., .. Brown, R. A. (2019). Anxiety sensitivity and smoking among Spanish-speaking Latinx smokers. Addictive Behaviors, 90, 55-61. https://doi.org/10.1016/j. addbeh.2018.10.022.

Zvolensky, M. J., Farris, S. G., Guillot, C. R., \& Leventhal, A. M. (2014). Anxiety sensitivity as an amplifier of subjective and behavioral tobacco abstinence effects. Drug and Alcohol Dependence, 142, 224-230. https://doi.org/10.1016/j. drugalcdep.2014.06.023.

Zvolensky, M. J., Yartz, A. R., Gregor, K., Gonzalez, A., \& Bernstein, A. (2008). Interoceptive exposure-based cessation intervention for smokers high in anxiety sensitivity: A case series. Journal of Cognitive Psychotherapy, 22(4), 346-365. https:// doi.org/10.1891/0889-8391.22.4.346. 